\title{
Erratum to: Something worth remembering: visual discrimination in sharks
}

\author{
Theodora Fuss • Vera Schluessel
}

Published online: 17 December 2014

(C) Springer-Verlag Berlin Heidelberg 2014

\section{Erratum to: Anim Cogn}

\section{DOI 10.1007/s10071-014-0815-3}

In the original publication, the reference citations beneath the Figs. 1 and 2 were published incorrectly. The corrected figures are given below.

The online version of the original article can be found under doi:10.1007/s10071-014-0815-3.

T. Fuss $(\bowtie) \cdot$ V. Schluessel

Institute of Zoology, Rheinische Friedrich-Wilhelms-University

Bonn, Meckenheimer Allee 169, 53115 Bonn, Germany

e-mail: thfuss@uni-bonn.de 
Fig. 1 Experimental setup located within the experimental basin, inside the white pavilion. The keyhole-shaped setup consisted of a starting compartment, a decision area and a frosted screen for projections, featuring a divider allowing for unambiguous choice-making (left and right). For the projections, a LED projector was used. Sharks were placed within the SC at the start of each trial. 1 feeders, 2 frosted screen for projection, 3 cable pulls to release feeders, $4 a$ guillotine door, $4 b$ cable pull to open guillotine door, 5 ceiling mounted fluorescent tubes (above pavilion roof)

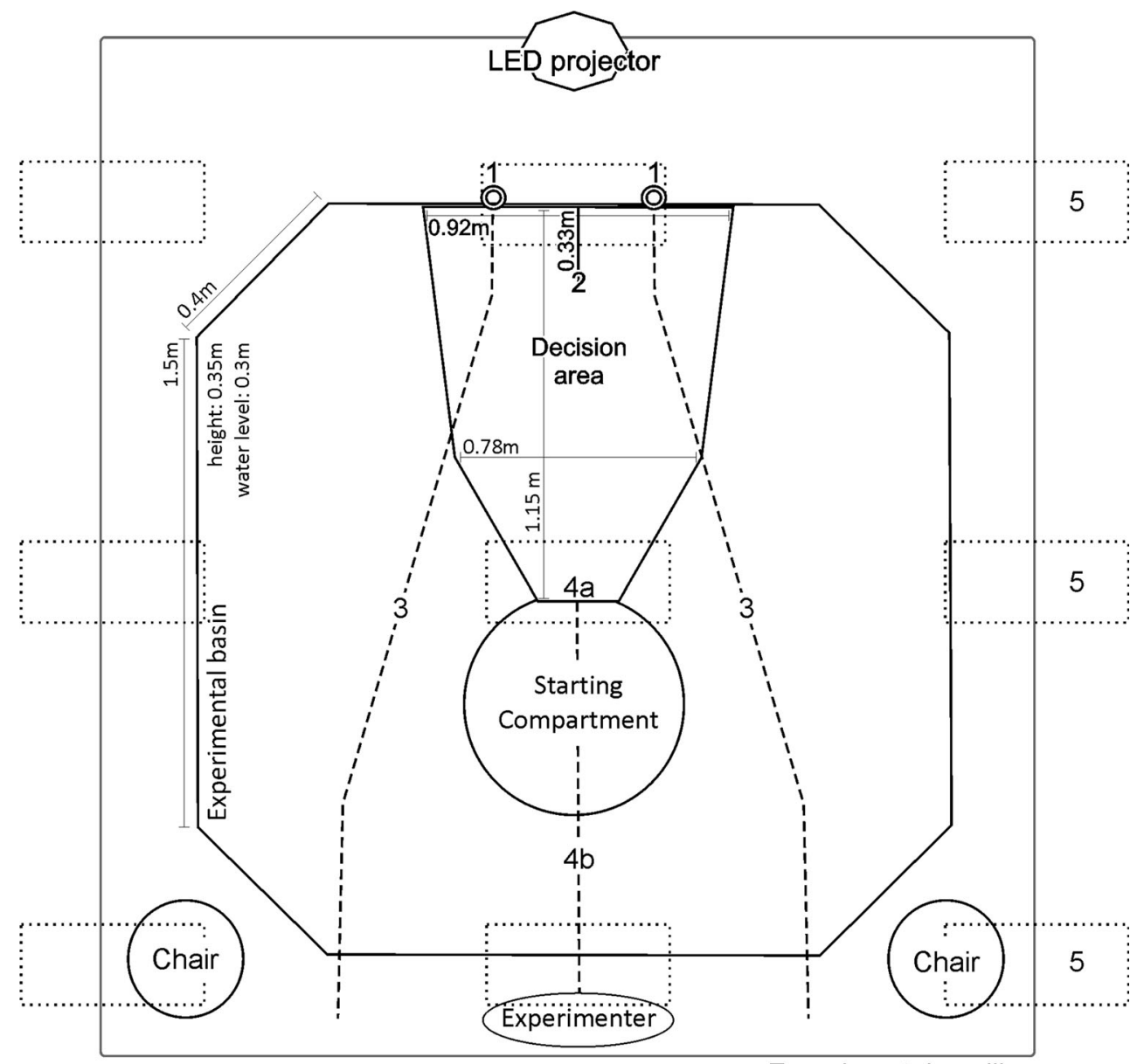

Experimental pavilion

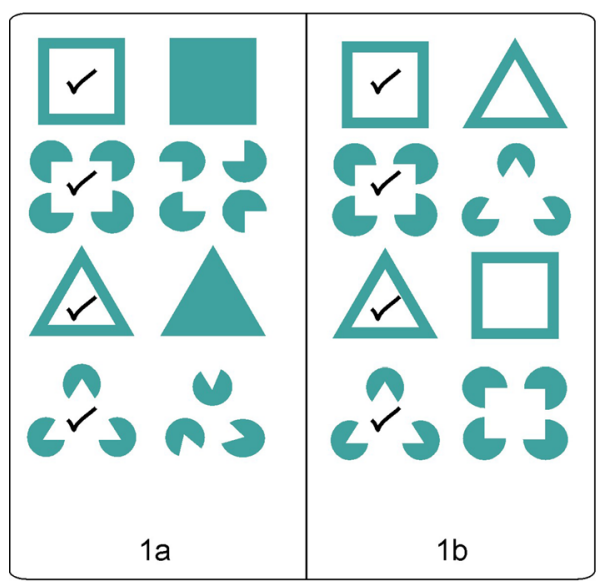

Experiment 1 Kanizsa Figures

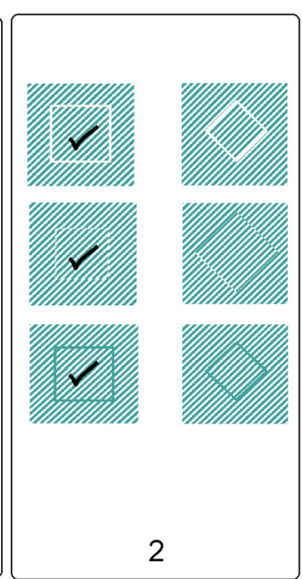

Experiment 2 Subjective contours

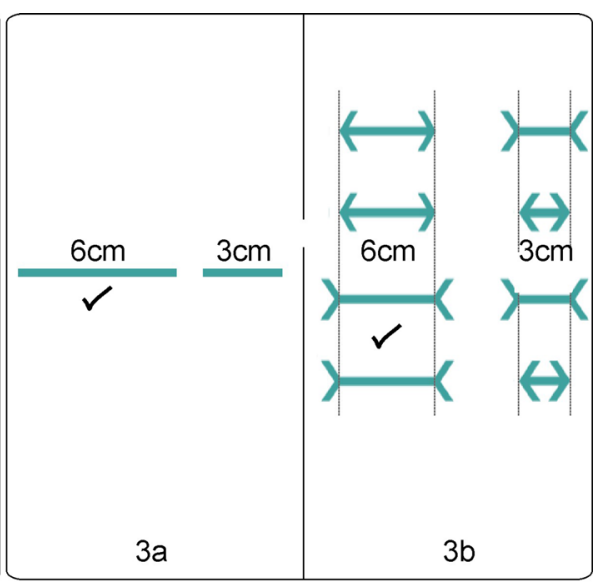

Experiment 3

Size Ratios \& Müller-Lyer deception

adopted from Fuss et al. 2014b

Fig. 2 Stimuli that were presented to each group during regular training for Experiments $1-3$ and accordingly, the memory retention test. The positive, rewarded stimulus is indicated by a checkmark 